Case Reports in
Gastroenterology
Case Rep Gastroenterol 2020;14:522-526

DOI: 10.1159/000508916

Published online: October 27, 2020

(C) 2020 The Author(s)

Published by S. Karger AG, Basel www.karger.com/crg

This article is licensed under the Creative Commons Attribution-NonCommercial 4.0 International License (CC BY-NC) (http://www.karger.com/Services/OpenAccessLicense). Usage and distribution for commercial purposes requires written permission.

\title{
Clostridium difficile Infection in a Very Young Infant with Pseudomembranous Colitis Noted on Endoscopy
}

\author{
Eric Tibesar \\ Pediatric Gastroenterology, Peyton Manning Children's Hospital, Indianapolis, IN, USA
}

\section{Keywords}

Pediatrics · Clostridium difficile · Colitis · Differential diagnosis · Gastrointestinal bleeding

\begin{abstract}
Clostridium difficile infection rates have been rising within the last decade and more pediatric patients have been suffering from this type of infection. However, this bacterium is a wellknown contaminant in the normal flora of the colon in patients under the age of 2 years, and therefore consensus guidelines have recommended against routine testing for this infection, unless clinically indicated. We present here a case of a very young infant who presented with symptoms of food refusal, poor weight gain, abdominal distention, and colitis noted on imaging. Endoscopic evaluation demonstrated the presence of pseudomembranous colitis, so the patient was treated with antibiotics against $C$. difficile and recovered fully. This case demonstrates the importance of keeping $C$. difficile colitis in your differential diagnosis, even at a very young age.

(C) 2020 The Author(s)

Published by S. Karger AG, Basel
\end{abstract}

\section{Introduction}

Clostridium difficile is a gram-positive, toxin-producing bacterium that causes a large amount of healthcare-associated diarrhea in the USA. It has become a significant form of morbidity in pediatric patients as the prevalence of this disease has increased in the last 10-20 


\section{Case Reports in Gastroenterology}

Case Rep Gastroenterol 2020;14:522-526 DOI: $10.1159 / 000508916$

(c) 2020 The Author(s). Published by S. Karger AG, Basel www.karger.com/crg

Tibesar: Clostridium difficile Infection in a Very Young Infant

years [1]. It is well known that $C$. difficile is a normal part of the fecal microbiota, and in pediatric individuals it has been shown to have a high carriage rate, especially in the younger population. Because of this high rate of carriage in children and especially in infants, consensus guidelines have recommended against routine testing for this organism in pediatric patients [1].

However, C. difficile infection in younger patients can cause significant symptoms such as failure to thrive, food refusal, severe dehydration with electrolyte imbalance, intractable diarrhea, and abdominal pain, which leads to significant morbidity and sometimes mortality. We here report on the case of a very young infant who presented with severe symptoms of weight loss, failure to thrive, food refusal, and abdominal distention and who was found to have pseudomembranes on colonoscopy, thus leading to the correct diagnosis and proper treatment.

\section{Case Presentation}

The patient was a 17-day-old term male infant who was admitted to the hospital due to concerns about feeding refusal, mildly elevated liver transaminases, and loose, frequent, watery stools with flecks of blood and mucus. The infant had initially been breast-fed for a few days, but then transitioned over to regular infant formula due to lack of maternal breast milk supply.

The initial workup in the hospital included blood tests, showing an elevated ALT of 141 $\mathrm{U} / \mathrm{L}$ with a normal AST and an albumin level of $1.8 \mathrm{~g} / \mathrm{dL}$. The C-reactive protein level was elevated at $3.6 \mathrm{mg} / \mathrm{dL}$, with a normal white blood cell count. On examination, the infant had a slight amount of abdominal distention, so an X-ray was obtained, showing possible wall thickening of the descending colon with a large amount of small bowel gas but no signs of obstruction or pneumatosis. An upper gastrointestinal study was also performed, showing no signs of anatomic obstruction or malrotation. Because of the slight thickening of the colon and concerns for possible Hirschsprung-associated enterocolitis, a barium enema was also conducted, and this showed distal wall thickening of the colon.

A blood culture, urine culture, and stool culture were conducted, and a lumbar puncture was performed with culture of the cerebrospinal fluid. The baby was started on empiric antibiotics, and all cultures showed no growth, but a Hemoccult test did come back positive. Repeat complete blood counts showed a dropping hemoglobin level from 9.8 down to $7.0 \mathrm{~g} / \mathrm{dL}$. The C-reactive protein level also increased to a peak of $16.6 \mathrm{mg} / \mathrm{dL}$. Over the next several days in the hospital, the patient remained on nasogastric tube feedings because of a lack of oral intake and concerns for weight loss, but the stools remained loose, watery, and with small amounts of visible blood.

Therefore, the decision was made to take the infant to the operating room for a colonoscopy and rectal suction biopsy. The visual appearance of the colon was notable, with multiple pseudomembranes next to a mildly inflamed and edematous mucosa (Fig. 1). The pathology from the biopsies showed acute colitis with necroinflammatory exudate consistent with $C$. difficile colitis. The rectal suction biopsies showed evidence of acute proctitis but were positive for ganglion cells. The patient was diagnosed with $C$. difficile enterocolitis and was switched over to IV metronidazole.

After a few days, his oral intake improved, and his stools became less frequent and more formed. He was ultimately discharged home, and at the follow-up appointment, he was no longer having any symptoms and was tolerating normal formula by mouth with excellent growth and normal development. 


\section{Case Reports in Gastroenterology}

Case Rep Gastroenterol 2020;14:522-526 DOI: $10.1159 / 000508916$

(c) 2020 The Author(s). Published by S. Karger AG, Basel www.karger.com/crg

Tibesar: Clostridium difficile Infection in a Very Young Infant

\section{Discussion and Conclusion}

C. difficile colitis is commonly caused by toxin A and toxin B infection and can have the appearance of pseudomembranes covering the mucosa of the colon on endoscopy. These exotoxins can infect the epithelial cells of the intestinal tract and cause a significant and sometimes severe inflammatory reaction $[2,3]$. This reaction can lead to both malabsorption in the intestines as well as intestinal leakage causing bloody diarrhea and abdominal pain. In pediatric patients, this can also lead to symptoms that include feeding refusal, failure to thrive, intestinal perforation, and possibly death.

It is well known that in infants and very young children, $C$. difficile is a bacterium that is part of the natural flora of the colon. It very rarely causes any significant symptoms in patients so young, and therefore consensus guidelines recommend not routinely testing for this infection unless clinically indicated [1]. Many times, false-positive tests can lead to inappropriate treatments and further complications from frequent antibiotic use, including the concern for drug-resistant bacteria.

In most adults, $C$. difficile colitis can be attributed to a nosocomial infection, as hospitalized patients are at high risk of contracting this bacterium. In addition, prior antibiotic use is a common finding in the history of patients who develop this infection. However, as with many infections and disease processes, this is not always the case in pediatric patients - especially in infants, who can develop C. difficile colitis without any history of hospitalization or prior antibiotic usage. There have been several reports in the literature of young patients diagnosed with $C$. difficile colitis, and very rarely any specific cause is found [4-9].

This case report presented the case of a very young infant who showed symptoms of food refusal, weight loss, and abnormal stools with concern for colitis on imaging tests. There was no history of any prior hospitalization or antibiotics and no sick contacts. The differential diagnosis for a similar presentation would be quite broad, but it certainly includes other types of infection, as infants are at high risk due to their compromised immune system. Other potential diagnoses would include milk protein colitis, Hirschsprung-associated enterocolitis, eosinophilic colitis, or other reactions to food in the diet.

After a thorough literature search, this case report is found to present the first published images of pseudomembranous colitis in an infant under the age of 1 month. Although $C$. difficile is still part of the normal flora in infants of this age, this case illustrates that in rare circumstances it can cause significant symptoms such as bloody diarrhea, failure to thrive, and abdominal distention with the possibility of intestinal perforation. It remains important that when infants present with similar symptoms, $C$. difficile colitis should be included in the differential diagnosis. Fortunately, the patient was diagnosed correctly using a combination of imaging and endoscopic evaluation, and after appropriate treatment, he did well and has had no further history of poor growth, failure to thrive, or developmental delay.

\section{Statement of Ethics}

The subjects have given their written informed consent to publish their child's case.

\section{Conflict of Interest Statement}

The author has no conflicts of interest to declare. 


\section{Case Reports in Gastroenterology}

\section{Funding Sources}

There were no funding sources for the preparation of this manuscript.

\section{References}

1 McDonald LC, Gerding DN, Johnson S, Bakken JS, Carroll KC, Coffin SE, et al. Clinical practice guidelines for Clostridium difficile infection in adults and children: 2017 update by the Infectious Diseases Society of America (IDSA) and Society for Healthcare Epidemiology of America (SHEA). Clin Infect Dis. 2018 Mar;66(7):e1-48.

2 Borali E, De Giacomo C. Clostridium difficile infection in children: a review. J Pediatr Gastroenterol Nutr. 2016 Dec;63(6):e130-40.

3 Musil V, Homola L, Vrba M, Braunová A, Kravalová T, Malá M, et al. Clostridium difficile infection and colonisation in children under 3 years of age: prospective comparative study. Epidemiol Mikrobiol Imunol. 2019;68(2):59-64.

4 Davis MY, Zhang H, Brannan LE, Carman RJ, Boone JH. Rapid change of fecal microbiome and disappearance of Clostridium difficile in a colonized infant after transition from breast milk to cow milk. Microbiome. 2016 Oct; 4(1):53.

5 Huang SC, Yang YJ, Lee CT. Rectal prolapse in a child: an unusual presentation of Clostridium difficileassociated pseudomembranous colitis. Pediatr Neonatol. 2011 Apr;52(2):110-2.

6 Stoesser N, Eyre DW, Quan TP, Godwin H, Pill G, Mbuvi E, et al.; Modernising Medical Microbiology Informatics Group (MMMIG). Epidemiology of Clostridium difficile in infants in Oxfordshire, UK: risk factors for colonization and carriage, and genetic overlap with regional C. difficile infection strains. PLoS One. 2017 Aug;12(8):e0182307.

7 Ferraris L, Couturier J, Eckert C, Delannoy J, Barbut F, Butel MJ, et al. Carriage and colonization of C. difficile in preterm neonates: a longitudinal prospective study. PLoS One. 2019 Feb;14(2):e0212568.

8 Hines AG, Freifeld A, Zhao X, Berry AA, Willett L, Iwen PC, et al. Clostridium difficile stool shedding in infants hospitalized in two neonatal intensive care units is lower than previous point prevalence estimates using molecular diagnostic methods. BMC Pediatr. 2018 Apr;18(1):137.

9 Kim EJ, Lee SH, Tchah H, Ryoo E. Effect of metronidazole in infants with bowel habit change: irrelative to the Clostridium difficile colonization. Pediatr Gastroenterol Hepatol Nutr. 2017 Mar;20(1):47-54. 
Case Reports in Gastroenterology
Case Rep Gastroenterol 2020;14:522-526

DOI: 10.1159/000508916

(c) 2020 The Author(s). Published by S. Karger AG, Basel www.karger.com/crg

Tibesar: Clostridium difficile Infection in a Very Young Infant
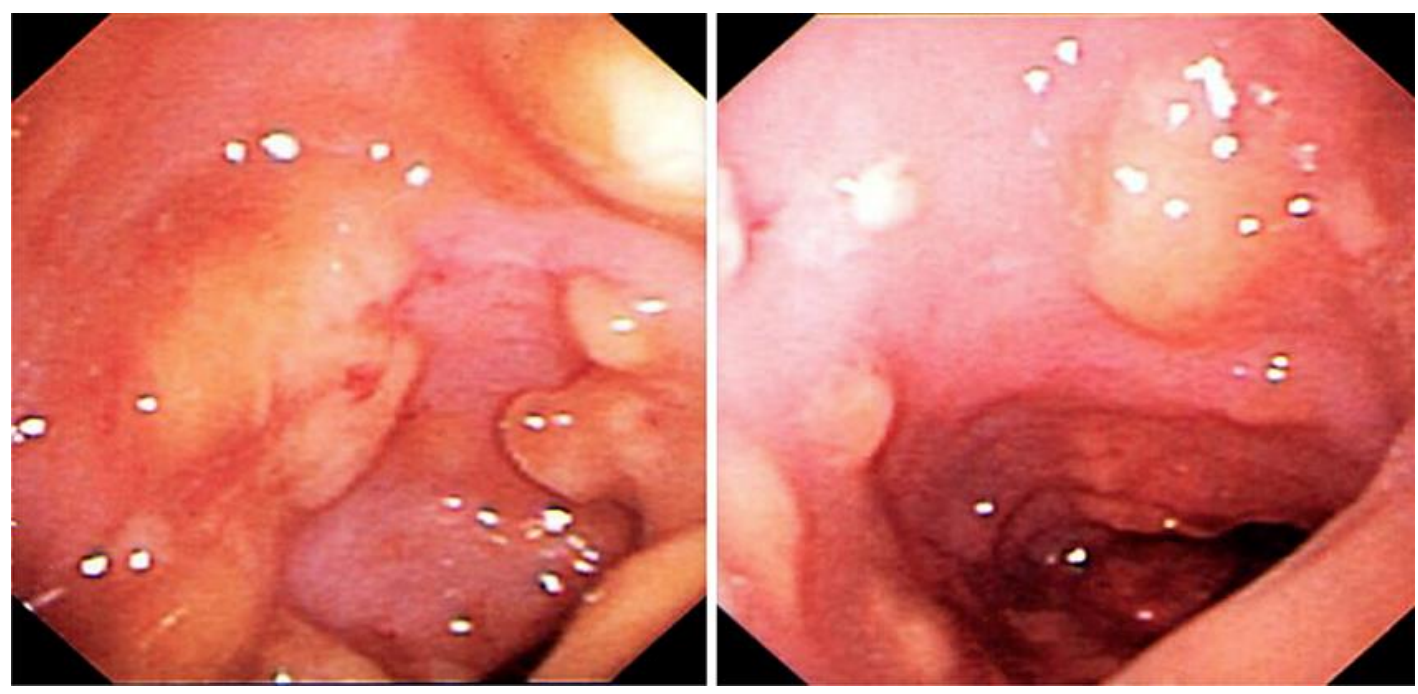

Fig. 1. Images from colonoscopy demonstrating the presence of pseudomembranes along with mildly edematous colonic mucosa mixed with normal-appearing mucosa. 